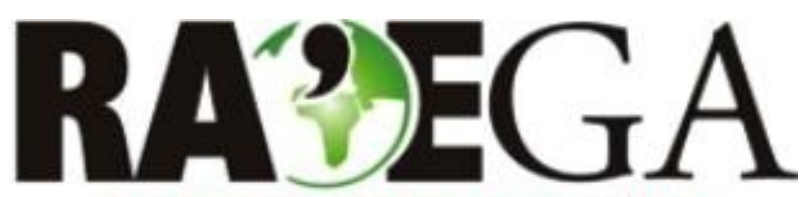

O ESPAÇO GEOGRÁFICO EM ANÁLISE

\title{
FINANCEIRIZAÇÃO DAS EMPRESAS DA CONSTRUÇÃO CIVIL E VERTICALIZAÇÃO EM LONDRINA-PR, BRASIL
}

\section{FINANCIALIZATION OF CONSTRUCTION SECTOR COMPANIES AND VERTICALIZATION IN LONDRINA-PR, BRASIL}

\author{
Edilson Luis Oliveira ${ }^{1}$, Tania Maria Fresca ${ }^{2}$
}

RESUMO

No Brasil, ao longo dos últimos 15 anos, fundos e investidores globais tornaram-se sócios de empresas do setor da construção civil. A chegada desses novos agentes econômicos se deu de formas diversas. Uma das formas pelas quais esses novos agentes econômicos conseguiram obter participação societária em incorporadoras foi a aquisição de um dado volume de ações negociadas em Bolsa de Valores, nos casos de empresas de capital aberto. No caso das empresas de capital fechado, a estratégia dos investidores globais foi a compra direta de parcelas societárias dos proprietários desse tipo de incorporadoras e construtoras. Esses processos são denominados no presente artigo como financeirização das empresas da construção civil. A financeirização tem implicações sobre o comportamento das empresas, intensificando sua atuação no mercado imobiliário. Observaram-se também mudanças nas estratégias espaciais das incorporadoras financeirizadas. Essas empresas expandiram suas áreas de atuação, abarcando novas cidades. A escolha das novas localidades atende a possibilidades de rápida valorização dos capitais investidos nos novos empreendimentos. O objetivo deste artigo é analisar geograficamente implicações do processo de financeirização das empresas de construção que têm sido ativas na verticalização de - Londrina-PR, no período de 2000-2015. Até o presente momento, verificou-se que as ações das empresas financeirizadas têm sido relativamente modestas, quando comparadas à atuação das empresas de capital local. A exceção tem sido a empresa MRV, que atua no segmento econômico. As demais empresas originárias de outras cidades enfrentam disputas acirradas com empresas locais, que têm se mostrado capazes de manter-se à frente na concorrência.

Palavras-chave:Fundos de Investimento; Empresas de Capital Aberto; Empresas de Capital Fechado; Estratégias Espaciais; Edifícios Altos.

\section{ABSTRACT}

In Brazil, for over the last 15 years, funds and global investors became partners of the construction sector companies. The arrival of these new economic agents occurred in several ways. One of the ways in which these new economic agents were able to obtain equity interest in real estate developers was the acquisition of a given volume of shares traded on the Stock Exchange, in the case of open capital companies. In the case of private companies, the strategy used by global investors was that of the direct purchase of equity shares of the owners of such real estate developers. These processes are referred to in this article as financialization of construction companies. The financialization has implications on the behavior of companies, intensifying its activities in real estate. It was also observed changes in spatial strategies of financialized real estate developers. These companies expanded their areas, encompassing new cities. The choice of new locations meet possibilities of rapid appreciation of capital invested in the production of new ventures. The purpose of this article is to geographically analyze the implications of the financialization process of the construction companies that have been active in the verticalization of - Londrina-PR, in the period from 2000 to 2015. Up to the present time, it has been verified that the actions of the financialized companies have been relatively modest, when compared to the performance of the local capital companies. The exception has been the MRV company, which operates in the economic segment. The other companies originating in other cities face fierce disputes with local companies, which have been able to stay ahead in the competition.

Key-words:Investment Funds; Open Capital Companies; Private Companies; Spatial Strategies; Tall Buildings.

Recebido em: 20/01/2016. Aceito em:01/08/2018

\footnotetext{
1 Universidade Estadual de Londrina, Londrina/PR, e-mail: edilsonluis64@gmail.com

2 Universidade Estadual de Londrina, Londrina/PR, e-mail: tania_geografia@yahoo.com.br
} 


\section{FINANCEIRIZAÇÃO DAS EMPRESAS DA CONSTRUÇÃO CIVIL E VERTICALIZAÇÃO EM LONDRINA-PR, BRASIL}

\section{INTRODUÇÃO}

O objetivo do presente artigo é analisar geograficamente as implicações do processo de financeirização de empresas da construção civil na verticalização da cidade de Londrina-PR, no período de 2000-2015.

Para desenvolver a análise e as explicações derivadas dessa questão, inicialmente são apresentados os aspectos teórico-metodológicos a partir dos quais se desenvolvem os encaminhamentos para a análise. Em seguida, discute-se o entendimento sobre o processo de financeirização subjacente à questão e sua incidência sobre o setor da construção civil no Brasil e sobre as incorporadoras e construtoras que produzem edifícios verticais residenciais em Londrina. Por fim, a análise converge para a situação geográfica dessa cidade, enfatizando as redefinições de sua inserção na divisão territorial do trabalho, bem como as implicações da financeirização presente nas incorporadoras atuantes na cidade, que são as responsáveis diretas pela verticalização que caracteriza a paisagem urbana de Londrina-PR.

Necessário considerar que, bibliografias sobre a temática têm sido direcionadas principalmente para as metrópoles brasileiras, enquanto cidades de outros escalões, como Londrina, ainda não apresentam análises das implicações do processo de financeirização na construção civil. Ao mesmo tempo, essa cidade coloca-se como uma das mais verticalizadas em termos percentuais do país, suscitando questionamentos a respeito das formas como esse processo vem sendo realizado.

Do ponto de vista dos procedimentos operacionais, os dados foram levantados junto ao 3.o Grupamento do Corpo de Bombeiros de Londrina através do Setor de Vistorias, a partir do qual se emite o Laudo de Vistoria de Conclusão de Obra - LVCO -, necessário para obtenção do Habite-se para edificações novas, reformadas ou ampliadas. Esse setor apresenta laudos de todos os edifícios construídos em Londrina e, a partir deles, obteve-se os dados sobre: localização, ano, área, construtora responsável, tamanho das unidades, dentre outros. Os dados foram levantados para edifícios verticais com quatro e mais pavimentos, conforme legislação municipal em vigor. O Código de Obras estabelece em seu artigo 140, que: "Para os edifícios que apresentarem cota superior a 10,00 m, medidas do piso do térreo ao piso do último pavimento, é obrigatória a instalação de elevador, sempre obedecendo, quanto à fabricação, instalação, manutenção e capacidade de tráfego, às normas recomendáveis pela Associação Brasileira de Normas Técnicas" (LONDRINA, 2011, n. p.). Em outros termos, se cada pavimento apresentar altura de $2,5 \mathrm{~m}$, isso implica que aquelas edificações com quatro pavimentos deveriam conter elevador. Se se acrescentar ainda a legislação federal a respeito da acessibilidade, tem-se mais um fator para a cota de 10 metros como exigência mínima para instalação de elevadores. Exceção nesse caso são as edificações verticais produzidas pelo poder público municipal na forma de conjuntos habitacionais, cuja legislação (LONDRINA, 2009) estabelece que só deverão ter elevadores aqueles com mais de cinco pavimentos. Observar que esses critérios são matéria de legislação municipal e, por isso, cambiante. É o caso da cidade de São Paulo, cujo código de obras em vigor (setembro de 2015) estabelece a colocação de elevadores para edificações com mais de cinco andares ou desnível superior a 12 metros (SÃO PAULO, 1992).

As referências a elevadores necessitam ser explicadas. O que define um prédio ou edifício vertical? Uma edificação com sete metros de altura pode ser considerada como edifício vertical? $O$ que estabelece as diferenças? Não há uma definição ou conceituação clara a esse respeito e nem mesmo no Código Civil brasileiro (BRASIL, 2002) há elementos que possam auxiliar tal compreensão. Considerando a legislação brasileira a respeito das normas técnicas de diversos órgãos (CREA, ABNT NBR, Corpo de Bombeiros etc.) e os códigos de obras de 


\section{FINANCEIRIZAÇÃO DAS EMPRESAS DA CONSTRUÇÃO CIVIL E VERTICALIZAÇÃO EM LONDRINA-PR, BRASIL}

diferentes municípios, pode-se entender que o que diferencia uma edificação de um edifício vertical é a altura e o uso ou a obrigatoriedade da presença de elevador. Com base em tais elementos é que se estabeleceu o número de quatro pavimentos para a realização da pesquisa em Londrina.

\section{ASPECTOS TEÓRICOS E METODOLÓGICOS NA ABORDAGEM DA QUESTÃO}

O primeiro elemento da questão proposta que requer algum grau de elucidação é: analisar geograficamente as implicações da financeirização e da própria verticalização. Teorizar em geografia exige o uso de instrumentos conceituais e metodológicos capazes de superar o nível fenomênico dado pela paisagem e elucidar os nexos explicativos da essência e da aparência dos processos e formas espaciais, presentes na estrutura de um dado lugar, em um dado momento. O lugar, nesse caso Londrina, apresenta-se como uma situação geográfica determinada, que, segundo
Santos (1991, p. 95), “[...] o que um lugar é, num dado momento, sempre constitui o resultado de ações de diversos elementos, que se dão em diferentes níveis. Esses elementos são variáveis pois mudam de significação através do tempo. A história é sem-fim, está sempre se refazendo".

A paisagem verticalizada de Londrina e o processo de verticalização correspondente, com seus diversos agentes sociais e desdobramentos, são os elementos centrais da situação geográfica a ser analisada e explicada no presente artigo. Os dados do Censo 2010 indicavam que, em Londrina, $20 \%$ dos domicílios particulares permanentes eram apartamentos (IBGE, 2010). Esse percentual é relativamente próximo ao que se verifica na cidade de São Paulo, a mais verticalizada do país, onde $28 \%$ dos domicílios são apartamentos. A magnitude desse processo e as formas espaciais correspondentes (Figura 1) também podem ser avaliadas a partir de outros dados.

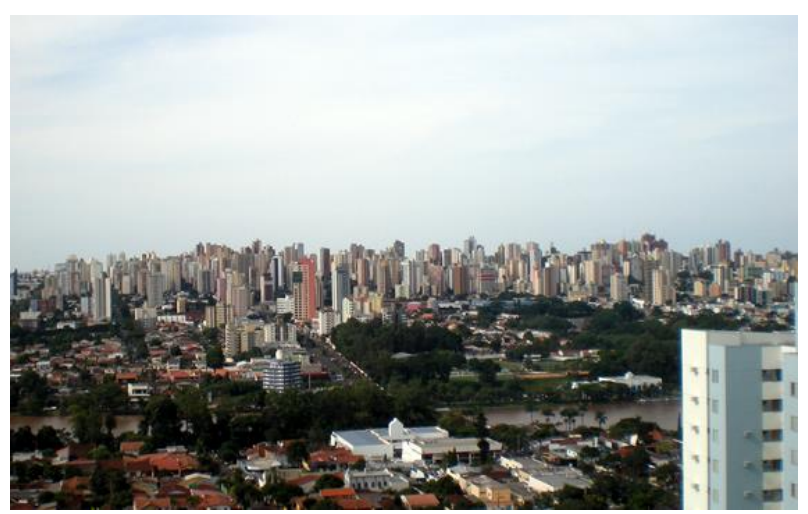

Figura 1 - Vista parcial da verticalização na área central de Londrina, 2015.Fonte: Autores (2017).

Com base em levantamento de campo realizado junto ao Corpo de Bombeiros, e trabalhos relativos ao processo de verticalização de Londrina (PASSOS, 2007; CASARIL, 2008, 2010, 2011; NASCIMENTO, 2015), verifica-se que, para o ano de 2013, havia 2111 edifícios de quatro ou mais pavimentos na cidade; computados nesse total estavam os edifícios em construção naquele ano. Do total, muitos são torres de mais de 30 pavimentos e predominam os edifícios de uso residencial. Segundo a empresa Emporis (2015), esse montante de edifícios coloca Londrina na condição de 12. cidade brasileira com mais edifícios altos.

Do ponto de vista analítico, a existência de tantos edifícios verticais reunidos na paisagem londrinense exige processos articulados de produção e consumo. Tais processos mantêm diversificadas relações de causalidade com a formação socioespacial (SANTOS, 1982) em suas várias escalas. 


\section{FINANCEIRIZAÇÃO DAS EMPRESAS DA CONSTRUÇÃO CIVIL E VERTICALIZAÇÃO EM LONDRINA-PR, BRASIL}

O recorte temporal a partir da qual se discute a situação geográfica de Londrina está apoiado nas redefinições da inserção da cidade na divisão territorial trabalho nas escalas regional, nacional e internacional. Essas redefinições, ao lado de aspectos econômicos conjunturais e políticas públicas de incentivo à construção civil, são fundamentais para compreender os processos de produção e consumo de edifícios verticais, ou seja, a forma como se integram produção e demanda solvável e que determina as dimensões do mercado imobiliário local no segmento de apartamentos residenciais. À luz dos conceitos adotados, a chegada de agentes externos e sua participação na verticalização londrinense, podem ser consideradas como um dos vetores da redefinição da inserção de Londrina na divisão territorial do trabalho.

Além do conceito de situação geográfica, utiliza-se como ferramentas conceituais as noções de "externo" e "interno" (SANTOS, 1991), empregando como referencial para definir o que é interno e o que é externo, as dimensões local e regional de Londrina. "O interno é tudo que, num momento dado, está já presente num lugar determinado. No interno, as variáveis têm a mesma dimensão do lugar, as dimensões se superpõem delimitadas pelo lugar. O interno é aquilo que, num momento dado, aparece como local. A escala do lugar confunde-se com sua própria existência" (SANTOS, 1991, p. 96). Com relação ao externo, “[...] é tudo cuja sede é fora do lugar e tem uma escala de ação maior que a do lugar, muito embora incida sobre ele. Cada lugar tem, pois, variáveis internas e externas" (SANTOS, 1991, p. 96-97).

Com base nessas noções e em razão de seu protagonismo e predomínio no processo de verticalização, definiu-se como principais agentes internos as incorporadoras e construtoras de capital fechado com sede em Londrina. Os agentes externos são as incorporadoras/construtoras com sedes em outras cidades e que sejam de capital aberto, contando ou não com participação de capital estrangeiro.

Em termos temporais o recorte foi a partir do ano de 2000, quando teve início a atuação de incorporadoras e construtoras de capitais abertos na cidade. Do ponto de vista processual, implícito na teoria geográfica, utilizaremos como ferramentas conceituais o "novo e o velho" e as combinações particulares entre eles, postas na situação geográfica. Desse modo, pretende-se expor as tensões geradas na concorrência interempresarial a partir da chegada de agentes externos, representantes do novo - as empresas financeirizadas da construção civil - e os reflexos e reações nas incorporadoras e construtoras locais. Revelamse, assim, as disputas no âmbito do mercado, do território e das normas criadas pelo Estado. Essas mediações são explicativas da situação geográfica e de seus vínculos com a divisão territorial do trabalho, especialmente da seletividade espacial que lhe é inerente, em suas múltiplas escalas. "O novo nem sempre é desejado pela estrutura hegemônica da sociedade. Para esta, há o novo que convém e o que não convém. $O$ novo pode ser recusado se traz uma ruptura que pode tirar a hegemonia das mãos de quem a detém" (SANTOS, 1991, p. 98).

Ressalta-se que, na base analítica aqui utilizada, um fator a considerar em uma situação geográfica são as normas. As normas explicitam autorizações para fazer ou interdições. Sua existência e vigência são decisivas para delimitação do período e para compreensão das inter-relações tecidas pelas mediações que explicam a situação geográfica. No caso particular da financeirização das incorporadoras e construtoras da construção civil, é de fundamental importância o reconhecimento das possibilidades abertas aos capitais envolvidos nesse setor industrial pelo Sistema Financeiro Imobiliário (SFI) instituído em 1997 (BRASIL, 1997) e pela legislação sobre patrimônio de afetação de incorporações imobiliárias (BRASIL, 2004).Assim, o Estado e o mercado (SANTOS, 1991) colocam-se como mais um par conceitual 


\section{FINANCEIRIZAÇÃO DAS EMPRESAS DA CONSTRUÇÃO CIVIL E VERTICALIZAÇÃO EM LONDRINA-PR, BRASIL}

a ser considerado nas análises construídas neste artigo.

Outro aspecto teórico e metodológico implícito neste texto e que merece breve discussão, é o entendimento subjacente às análises desenvolvidas sobre o processo de financeirização de empresas da construção civil, particularmente as empresas que atuam no segmento residencial. $O$ processo de financeirização, tal como entendido nesse texto, compreende especificamente a participação de fundos e investidores globais em incorporadoras e construtoras do setor da construção civil brasileiro. Essa participação se dá por meio da aquisição de um dado volume de ações de empresas de capital aberto ou por meio da compra de parcelas societárias de empresas do setor, antes mesmo da abertura de seu capital em Bolsa de Valores. Desta forma, ficam excluídas da presente análise as manifestações da financeirização que compreendem a emissão de papéis, cuja valorização se dá por meio da captação e antecipação de renda futura, a exemplo dos Certificados de Recebíveis Imobiliários (CRI).A discussão proposta neste texto restringe-se à financeirização das empresas da construção civil atuantes no segmento residencial, analisadas principalmente na condição de agentes produtores do espaço urbano (CORRÊA, 1995) e não à financeirização do setor imobiliário como um todo.

Historicamente a construção civil se definiu como uma indústria de baixa composição orgânica de capital e intensiva em trabalho. Dadas suas características técnicas e políticas, foi ao longo do tempo tomada como um dos suportes de políticas econômicas anticíclicas. Quase sempre beneficiada com subsídios oficiais, as concessões apoiaram-se no argumento da geração de empregos de forma rápida e que absorviam quantidades significativas de trabalhadores com baixa escolaridade e qualificação, auxiliando na recuperação da economia como um todo em fases recessivas (BONDUKI, 1994; BOLAFFI, 1985).
O desenvolvimento da construção civil em bases industriais está relacionado às transformações sociais, econômicas e políticas da sociedade brasileira, que ocorrem em simultaneidade e sintonia com o processo de urbanização. O percurso das transformações que conduzem a formação do circuito imobiliário no Brasil, incluindo capitais mercantis e capitais industriais, é bastante intrincado e não cabe aqui reproduzi-lo. Há bibliografia abundante a esse respeito (MELO, 1990; BONDUKI, 2009; FIX, 2011; VEDROSSI, 2002; VARGAS, 1992; BALL, 1992 etc.). Mas a construção civil brasileira, como outros ramos da produção, desenvolveu-se em articulação com o Estado. Ao longo dos últimos 50 anos, as empresas desse setor mostraram-se dependentes diretas da demanda gerada pelo Estado ou da regulação da demanda habitacional via políticas específicas de habitação, no âmbito do Sistema Financeiro da Habitação (SFH) e do extinto Banco Nacional da Habitação (BNH).

$\mathrm{O}$ encerramento do BHN em meados nos anos 1980 repercutiu negativamente sobre as empresas da construção civil, especialmente sobre as incorporadoras responsáveis pela verticalização. Aproximadamente até o final dos anos 1990, a política habitacional no país foi muito enfraquecida, com efeitos negativos para construtoras e incorporadoras no que tange à obtenção de financiamentos com baixa taxa de juros. O financiamento para o mercado consumidor também se mostrou limitado e dependente da política habitacional.

A partir de 1997, com a institucionalização do Sistema Financeiro Imobiliário (BRASIL, 1997), estabeleceu-se outra dinâmica para o mercado imobiliário como um todo. A ampliação do crédito e os novos poderes dos fornecedores de crédito definidos com a Alienação Fiduciária - que concede ao credor a posse do imóvel até quitação final dos débitos por parte do mutuário - estimularam a ampliação da oferta de crédito privado oriundo de instituições bancárias, ao consumidor de unidades habitacionais com capacidade de 


\section{FINANCEIRIZAÇÃO DAS EMPRESAS DA CONSTRUÇÃO CIVIL E VERTICALIZAÇÃO EM LONDRINA-PR, BRASIL}

pagamento comprovada.A conjuntura delimitada pelo novo marco regulatório especificado pelo SFI incidiu, com mais intensidade, nos segmentos do mercado imobiliário voltados para o setor corporativo, incluindo torres de escritório, grandes empreendimentos comerciais como shopping centers, hotéis e outros (ROYER, 2009; FIX, 2009, 2011). Mas a Política Nacional de Habitação (PNH), implantada a partir de 2003, permitiu a criação de mecanismos de complementaridade entre o Sistema Financeiro Imobiliário e o Sistema Financeiro da Habitação-SFH. Um desses mecanismos foi a constituição do subsistema de habitação de mercado (CASTRO, SHIMBO, 2010).

A redução da inflação e as novas normas como a já citada Lei Federal, à qual se juntou a Lei Federal 10.931, de 2004 (BRASIL, 2004), estabeleceram um novo patamar de segurança jurídica para instituições concedentes de crédito imobiliário. Essa lei instituiu o patrimônio de afetação, isto é, determinou que cada empreendimento possuísse patrimônio específico, separado do patrimônio da incorporadora, impedindo que recursos de um empreendimento sejam transferidos a outro. Estabeleceu ainda o valor do incontroverso que, em caso de tramitação de ação judicial que porventura questione itens do contrato, como a taxa de juros, determina que parcelas do financiamento devidas pelo mutuário continuem a ser pagas, mediante depósito em juízo.

Em conjunto com a alienação fiduciária, essas normas, ao ampliarem a segurança jurídica para entidades financiadoras, possibilitaram um momento de forte ampliação do crédito imobiliário para aquisição de imóveis novos e usados. Além de ampliar a segurança jurídica, o Governo Federal liberou recursos do Sistema Brasileiro de Empréstimo e Poupança (SBPE), que estavam retidos no Banco Central por meio de recolhimento compulsório. O resultado foi um crescimento expressivo do volume de recursos injetados no circuito imobiliário.
A expansão do crédito, que inclui financiamento à produção e a aquisição de imóveis novos e usados, proporcionou às incorporadoras oportunidades de expansão de suas atividades e captação de outros recursos no mercado financeiro (BIANCARELLI, LODI, 2009; SANFELICI, 2013; BOTELHO, 2007). A redução das restrições do mercado de consumo residencial, dada pelas novas linhas de financiamento com mais baixas taxas de juros, propiciou a formação de empresas de tamanhos e capacidades técnicas e financeiras variadas. Convivem atualmente no subsetor de edificações, desde pequenos produtores individuais de casas, construtoras pequenas e médias e grandes corporações internacionalizadas voltadas para construção residencial.

As políticas públicas e os subsídios governamentais tiveram papel mais acentuado na expansão da demanda e na financeirização específica das empresas da construção civil, produtoras da verticalização residencial. Para o chamado segmento econômico do mercado imobiliário habitacional (SHIMBO, 2012), constituído por imóveis com preço entre 60 e 200 mil reais, os subsídios do Programa Minha Casa Minha Vida (PMCMV) foram fundamentais para inserir no mercado todo um grupo de pessoas que necessitavam adquirir imóveis residenciais, mas que não possuíam meios pra ter acesso ao crédito bancário disponível.

Tanto assim que, o volume do saldo da carteira de crédito para aquisição e financiamento imobiliário cresceu 5,7 vezes $(474,8 \%)$ entre 2008 e 2013, segundo dados do Banco Central; do total de recursos direcionados, o crédito imobiliário saltou de $15,7 \%$ em janeiro de 2008 , para $33 \%$ em dezembro de 2013; o crédito imobiliário destinado à pessoa jurídica teve crescimento real de $601 \%$ entre $2008-2003$ e o crédito para pessoa física aumentou em 459\% acima da inflação no período citado; a relação crédito imobiliário/PIB evoluiu de 1,8\% em 2008 para 8,22\% em 2013 (DIEESE, 2014). 


\section{FINANCEIRIZAÇÃO DAS EMPRESAS DA CONSTRUÇÃO CIVIL E VERTICALIZAÇÃO EM LONDRINA-PR, BRASIL}

\begin{abstract}
Considerando esses aspectos particulares do desenvolvimento econômico brasileiro recente, pode-se argumentar que o processo de financeirização das empresas da construção civil brasileira segue um percurso de desenvolvimento profundamente articulado com os fundos públicos destinados às políticas habitacionais.
\end{abstract}

Há uma particularidade cujos desdobramentos geográficos são analisados para Londrina. A particularidade é: a interrelação entre expansão do fundo público para ampliar a demanda solvável da habitação verticalizada, via subsídios do Programa Minha Casa Minha Vida, e os aportes de capital dinheiro, realizados por meio de captação no mercado de capitais. Um dos desdobramentos dessa particularidade, relacionada à participação de fundos financeiros globalizados em empresas da construção civil, é a ampliação da oferta de imóveis em dadas localidades e para determinados segmentos do mercado consumidor.

Nessa perspectiva teórica, a discussão sobre o capital financeiro, entendido como um novo tipo de capital (PINTO, 1994), que reúne em si características do capital industrial (valorização) e do capital bancário (liquidez) e que se constitui como tendência inerente ao capitalismo monopolista, remonta a autores clássicos como Lenin (1979) e Hilferding (1985). Contudo a financeirização atual compreende também novos elementos, alguns deles particulares à formação socioespacial brasileira, como no caso da forma específica em que se estabelece a articulação em relação ao fundo público.

Como dado novo, destacam-se as tendências de preponderância da esfera financeira sobre a produtiva e a de relativa autonomização da esfera financeira (CHESNAIS, 2005). Entende-se que, no caso da financeirização das empresas da construção civil, atenção especial deve ser dispensada ao modo como se entrelaçam o capital financeiro e o industrial, particularmente as formas de governança corporativa nas empresas, em que investidores institucionais como Fundos Equity se fazem presentes (VERDI, 2002, p.27).

A importância da nova relação expressa pelo termo genérico sistema de governança reside na capacidade dos novos participantes, os investidores institucionais tais como os fundos globais e/ou grandes investidores individuais, de direcionarem decisões estratégicas e táticas das empresas que controlam ou nas quais têm participação acionária suficiente e, no contexto dessas decisões estratégicas, incluem-se decisões sobre onde produzir novos edifícios, para quais mercados locais e/ou regionais se expandirem e imposição de lógica de curto prazo.

Essas observações permitem compreender a tensão gerada entre os objetivos de investidores e fundos, diretamente ligados à lógica de curto prazo, e as determinações específicas do ciclo de capital na construção civil voltada para a produção de unidades residenciais, que requer períodos longos de rotação, da ordem de 3 a 4 anos no mínimo (VEDROSSI, 2002, p.2-3).

Os possíveis ganhos dos investidores envolvem tanto a rentabilidade das empresas incorporadoras como uma possível alta na cotação de suas ações na Bolsa de Valores, estimulada pelo aumento do valor geral de vendas das empresas. Diante dessas condições há um potencial enfraquecimento da sintonia entre gestão da produção e governança corporativa da empresa, em face dos objetivos e horizontes temporais distintos.

Esses subsídios teóricos são pontos de reflexão que serão contrastados com as observações sobre os agentes externos que integram a situação geográfica de Londrina. Importa principalmente discutir até que ponto essas tendências gerais trazem para a verticalização londrinense novas dinâmicas e como o lugar (situação geográfica em dado período) acolhe ou repele, no todo ou em parte, os desdobramentos das estratégias espaciais dos agentes externos, nesse caso, empresas incorporadoras e construtoras financeirizadas. 


\section{FINANCEIRIZAÇÃO DAS EMPRESAS DA CONSTRUÇÃO CIVIL E VERTICALIZAÇÃO EM LONDRINA-PR, BRASIL}

\section{FINANCEIRIZAÇÃO NA CONSTRUÇÃO CIVIL E AGENTES EXTERNOS EM LONDRINA}

Com poucas exceções, até o início dos anos 2000, as incorporadoras/construtoras responsáveis pela produção de edifícios verticais em Londrina eram empresas locais (PASSOS, 2007; CASARIL, 2011). Entre 2000 e 2013, considerando apenas os edifícios verticais produzidos por empresas e voltados para o mercado residencial, ou seja, excluindo-se os edifícios produzidos no sistema preço de custo ou edifícios comerciais, verificou-se a presença de 48 construtoras e incorporadoras envolvidas na construção de 207 empreendimentos residenciais na cidade. Desse total, $79 \%$ eram empresas locais (31 empresas). Apesar da imensa maioria ainda ser composta por empresas de origem local, nota-se certo grau de participação de agentes externos no processo de verticalização londrinense.

Se considerar a área construída em empreendimentos verticais residenciais como critério principal de hierarquização das empresas, o cenário que segue é: a) as 48 empresas atuantes em Londrina entre 2000 e 2013 produziram 3.166.227,5 $\mathrm{m}^{2}$ em 207 empreendimentos; b) das 48 empresas, $21 \%$ do total possuíam sede fora de Londrina, ou seja, eram agentes externos que produziram apenas $10 \%$ da área construída no período; c) as empresas locais (79\% do total de empresas) construíram nada menos que $89 \%$ dos 3.166.227,5 $\mathrm{m}^{2}$ de edifícios residenciais em Londrina; d) das 48 empresas atuantes, 15 empresas produziram em conjunto, $88 \%$ do total de área construída. Individualmente cada uma dessas empresas foi responsável pela edificação de pelo menos $1 \%$ do total da área construída no período considerado.

Há forte concentração da verticalização londrinense em um grupo reduzido de empresas. Do grupo de 15 empresas incorporadoras representado no quadro 1, destacam-se quatro empresas como agentes externos: MRV, Rossi Residencial, Thá e Tenda, sendo que a Thá e a Rossi associaram-se na produção de um empreendimento residencial em Londrina. Essas empresas são capazes de modificar dinâmicas do mercado local e estabelecer novas bases de concorrência com as grandes empresas londrinenses.

Essa capacidade deriva da demanda reprimida por habitações, expressa no chamado déficit habitacional, das possibilidades abertas pelo aumento do volume de capital acessível às empresas da construção civil e das novas autorizações constituídas pelo novo marco regulatório relativas a denominada habitação social de mercado, efetivada a partir de 2009, com a primeira fase do PMCMV.

\begin{tabular}{|c|c|c|c|c|}
\hline Incorporadora/Construtora & $\begin{array}{c}\text { Área Construída 2000-2013 } \\
\left(\mathbf{m}^{\mathbf{2}}\right)\end{array}$ & $\begin{array}{c}\text { Área } \\
\text { Construída \% }\end{array}$ & N.o Empreend. & N.o Empreend. \% \\
\hline Plaenge Empreendimentos Ltda. & $682.678,0$ & 24,4 & 30 & 14,5 \\
\hline A Yoshii Engenharia e Const. Ltda & $461.518,3$ & 16,5 & 21 & 10,1 \\
\hline Vectra Empreendimentos Ltda. & $294.875,3$ & 10,5 & 13 & 6,3 \\
\hline Quadra Construtora Ltda & $219.969,5$ & 7,8 & 16 & 7,7 \\
\hline Galmo Engenharia e construções & $195.117,2$ & 7,0 & 11 & 5,3 \\
\hline Vanguard Emp.Imobiliários Ltda. & $190.628,9$ & 6,8 & 8 & 3,9 \\
\hline MRV Engenharia e Participações S.A. & $189.351,2$ & 6,8 & 13 & 6,3 \\
\hline Yticon Const.e Incorporadora Ltda. & $180.243,5$ & 6,4 & 8 & 3,9 \\
\hline Artenge Construções Civis Ltda. & $131.450,8$ & 4,7 & 9 & 4,3 \\
\hline Favoretto Empreendimentos & $91.639,3$ & 3,3 & 4 & 1,9 \\
\hline Construtora Almanary & $37.834,8$ & 1,3 & 3 & 1,4 \\
\hline COHAB (FMM Construções Civis) & $33.340,9$ & 1,2 & 3 & 1,4 \\
\hline Tenda / FGM Incorporações & $31.649,5$ & 1,1 & 1 & 0,5 \\
\hline Thá / Rossi & $31.582,0$ & 1,1 & 1 & 0,5 \\
\hline Serteng & $30.719,7$ & 1,1 & 4 & 1,9 \\
\hline Total parcial (15 empresas) & $2.802 .598,9$ & 88,5 & 145 & 70,0 \\
\hline Total geral (48 empresas) & $3.166 .227,5$ & 100,0 & 207 & 100,0 \\
\hline
\end{tabular}

Quadro 1 - Principais Incorporadoras/Construtoras atuantes em Londrina: 2000 a 2013.Fonte: Corpo de Bombeiros, 2014. 


\section{FINANCEIRIZAÇÃO DAS EMPRESAS DA CONSTRUÇÃO CIVIL E VERTICALIZAÇÃO EM LONDRINA-PR, BRASIL}

A questão que se coloca é a seguinte: como essa tendência geral atinge Londrina e se integra à situação geográfica presente? 0 quadro 1 traz as 15 principais construtoras e incorporadoras que atuaram em Londrina entre 2000-2013.

Chama a atenção o fato de que as seis primeiras colocadas são empresas londrinenses. Considerando os objetivos desse artigo, dentre os agentes externos com maior impacto na produção de edifícios verticais em Londrina, destaca-se a MRV, empresa nacional de capital aberto com sede em Belo Horizonte- MG. As possibilidades de atuação da MRV no chamado segmento econômico tornaram a empresa atraente para o capital financeiro, na medida em que a presença do fundo público dinamizou os negócios em torno desse segmento, sendo a empresa "[...] líder em contratos no MCMV, superando de longe as concorrentes, com participação estimada em $12 \%$ no volume total do programa" (FIX, 2011. p.157).

Sua atuação na produção de unidades habitacionais para faixas de renda atendidas pelo Minha Casa Minha Vida foi também uma das razões para que a empresa recebesse os aportes de capital por meio da Bolsa de Valores ou da compra de lotes de ações por fundos globais. O capital dinheiro entrou na empresa por meio de aquisições de lotes de ações por parte de fundos equity ou assemelhados e ofertas públicas de ações em 2007 e 2008. Com isso, a antiga empresa de base familiar modificou sua estrutura de propriedade e fundos globais passaram a participar de sua gestão (TONE, 2010; FIX, 2011), conforme quadro 2.

\begin{tabular}{|c|c|c|c|c|}
\hline \multirow{2}{*}{ Acionista } & \multirow{2}{*}{ Controlador } & \multirow{2}{*}{ Nacionalidade Majoritária } & \multicolumn{2}{|c|}{ Ações Ordinárias } \\
\hline & & & Quantidade & (\%) \\
\hline Rubens M. Teixeira de Souza & Sim & Brasileiro & 155.297 .730 & 34,58 \\
\hline Orbis Inv. Management Limited & Não & Bermuda & 51.410 .761 & 11,45 \\
\hline Janus Capital Management LLC & Não & EUA & 22.744 .500 & 5,06 \\
\hline M\&G Inv. Management Limited & Não & Inglesa & 22.469 .950 & 5 \\
\hline Ações em Tesouraria & Não & - & 7.979 .952 & 1,78 \\
\hline
\end{tabular}

Quadro 2 - Posição acionária da MRV em 2014. Fonte: Ecoinfo, 2015.

O faturamento da MRV foi multiplicado por 10 entre 2007 e 2010 (FIX, 2011, p. 156) e a empresa passou a atuar em mais de 130 cidades brasileiras e em 20 das 27 unidades federativas (MRV, 2015). Fundada no final dos anos de 1970, a empresa cresceu produzindo imóveis residenciais para as classes $C$ e D. Possuía o maior número de empreendimentos financiados pelo PMCMV até 2013, concentrados numericamente em cidades dos estados das Regiões Sul e Sudeste.

Entre 2000 e 2013 a MRV foi responsável por 13 empreendimentos em Londrina, totalizando 189.351,2 $\mathrm{m}^{2}$, o equivalente a $6,8 \%$ da área construída por empresas no período considerado, conforme quadro 3. Segundo Nascimento (2015), a atuação da MRV em Londrina é parte de seu processo de expansão para o Paraná. Os principais fatores que influenciaram essa expansão foram: o tamanho da cidade, o potencial econômico e a dimensão da verticalização. $A$ área construída pela MRV em Londrina correspondeu a $2,2 \%$ de seu total nacional, segundo o ranking ITC 2014 (NASCIMENTO, 2015, p.117).Como se pode notar pelos dados do quadro 3, a maior parcela dos empreendimentos da MRV em Londrina concentrou-se entre os anos de 2009 e 2013, ou seja, no período de vigência do PMCMV.

\begin{tabular}{|c|c|c|}
\hline Ano & Empreendimentos & Área Construída $\left(\mathrm{m}^{2}\right)$ \\
\hline 2000 & Residencial Rio de Janeiro & $2.456,32$ \\
\hline 2002 & Residencial Lancaster & $7.630,26$ \\
\hline 2009 & Residencial SpazioLas Palmas & $6.706,34$ \\
\hline 2009 & Residencial Villa Bella & $27.705,97$ \\
\hline 2010 & ResidenceSpazio La Luna & $11.111,40$ \\
\hline
\end{tabular}


OLIVEIRA, E. L.; FRESCA, T. M.

\section{FINANCEIRIZAÇÃO DAS EMPRESAS DA CONSTRUÇÃO CIVIL E VERTICALIZAÇÃO EM LONDRINA-PR, BRASIL}

\begin{tabular}{|c|c|c|}
2010 & ResidenceSpazioLas Vegas & $11.629,12$ \\
\hline 2010 & Residencial SpazioLumiere & $9.903,11$ \\
\hline 2010 & Residencial Spazio La Ville & $8.440,11$ \\
\hline 2011 & Blocos Residenciais & $9.499,09$ \\
\hline 2012 & Residencial Leopoldina & $49.522,74$ \\
\hline 2012 & Residencial Spazio La Fenice & $8.877,14$ \\
\hline 2012 & Conjunto Res. I Spazio Lotus & $28.064,04$ \\
\hline 2012 & Residencial Spazio Le Mont & $7.805,60$ \\
\hline Total & 13 empreendimentos & $189.351,24$ \\
\hline
\end{tabular}

Quadro 3 - Empreendimentos da MRV Engenharia S/A em Londrina/PR: 2000 a 2013. Fonte: Corpo de Bombeiros, 2014.

Os edifícios verticais dessa empresa em Londrina acompanharam a tendência geral de seus empreendimentos na escala nacional. São voltados preferencialmente para famílias com renda média entre $\mathrm{R} \$ 1.600,00$ e $\mathrm{R} \$ 5.000,00$, ou seja, consumidores potencialmente aptos a obter subsídios do PMCMV. De acordo com Nascimento (2015), os empreendimentos da MRV estão localizados em áreas cujos terrenos têm preços menores no mercado e, portanto, estão localizados fora das áreas de maior valorização imobiliária. Como mencionado, outras empresas financeirizadas também ingressaram no mercado londrinense. São elas: Thá, Rossi e Tenda. Fundada em 1895, a empresa Thá tem sede em Curitiba e sólida atuação no mercado paranaense. A partir de 2011, a Thá ingressou no mercado londrinense de produção de edifícios e fez seu primeiro empreendimento na cidade em parceria com a Rossi, outra empresa de capital aberto. A transformação da Thá de construtora e incorporadora familiar em empresa financeirizada ocorreu em 2012, com a aquisição do controle dessa pelo fundo global EquityInternational, criado pelo investidor norte americano Sam Zaell, que tem o foco de suas atividades no circuito imobiliário.

Juntamente à empresa Thá, a Rossi Residencial também passou a atuar em Londrina. Essas duas empresas associaram-se para realizar um empreendimento residencial denominado Victoria Parque, situado na Gleba Palhano, vizinho ao Shopping Catuaí.

A Rossi desenvolveu ainda um empreendimento comercial composto por duas torres de escritório: o PalhanoBussines Center, situado na Avenida Airton Senna, principal via de circulação da Gleba Palhano, localizada na porção sudoeste da cidade. Essas referências de localização têm por objetivo indicar que essas duas empresas iniciaram suas ações em Londrina disputando localização de seus empreendimentos em uma área intensamente valorizada da cidade. A associação entre Thá e Rossi Residencial já foi desfeita e cada empresa segue atuando isoladamente. Em diálogo informal com representante que atuou nas duas empresas, indicou-se que ambas pretendem se estabelecer no mercado londrinense, dando sequência com novos empreendimentos que estão em fase de estudos. Outra vertente das ações dessas empresas tem sido a ampliação de seu banco de terras na cidade.

Fundada em 1980, a Rossi Residencial foi uma das primeiras empresas a alongar os prazos de financiamento de seus imóveis, por meio do chamado "plano 100" lançado em 1992. Iniciou sua trajetória de financeirização em 1997, quando captou US\$ 100 milhões com ações emitidas na Bolsa de Valores de São Paulo (Bovespa) e também Bolsa de Nova York. Em 2006 a Rossi passou a fazer parte do Novo Mercado da Bovespa. O Novo Mercado reúne empresas que assumem compromissos adicionais àqueles previstos na legislação em termos de governança. Dessa forma, as empresas integrantes do Novo Mercado da Bovespa comprometem-se a prestar informações que permitam e facilitem aos acionistas, independentemente de sua condição de controlador ou de investidor, acompanhar e fiscalizar a administração da empresa. 


\section{FINANCEIRIZAÇÃO DAS EMPRESAS DA CONSTRUÇÃO CIVIL E VERTICALIZAÇÃO EM LONDRINA-PR, BRASIL}

A importância de se considerar a financeirização de empresas da construção civil, especialmente quando esse processo envolve a captação de recursos em Bolsas de Valores, pode ser avaliada tendo como base a magnitude dos recursos injetados na Rossi. Entre 2006 quando passou a integrar o Novo Mercado da Bovespa - e 2010, quando completou 30 anos de existência, a empresa captou $\mathrm{R} \$ 1,45$ bilhões. Isso permitiu que houvesse expansão territorial de sua atuação com abertura de novos escritórios nas Regiões Sudeste, Sul e Nordeste, criação de fábricas de pré-moldados em cinco diferentes estados brasileiros e Distrito Federal. Diversificou seus negócios intensificando a participação tanto na produção de imóveis de alto padrão quanto no segmento popular. Passou a atuar em associação com incorporadoras regionais, adquiriu outra e passou também a atuar no segmento de shopping centers, em cidades de porte médio (ROSSI, 2015).

Atualmente o controle da Rossi parece ainda permanecer nas mãos de representantes da família fundadora da empresa. Essa informação está baseada em deduções a partir de informações disponibilizadas pelo BM\&FBovespa, em razão dessa pertencer ao segmento Novo Mercado Bovespa, conforme quadro 4. A atuação da Rossi em Londrina ainda é recente e relativamente restrita, porém, dado seu poder financeiro, é possível que venha a desenvolver ações estratégicas e táticas que alterem substancialmente a convivência competitiva já estabelecida com as empresas de capital fechado local.

A empresa Tenda é parte do Grupo Gafisa de São Paulo-SP, que, por sua vez, nasceu da Gomes de Almeida Fernandes, empresa familiar fundada na década de 1950. Segundo Fix (2011, p.153), em 1997 o Grupo Gafisa teve parte de seu capital adquirido pela GP Investimentos, que é um fundo encarregado da gestão de recursos de terceiros. Essa aquisição se deu antes da Gafisa realizar oferta pública de ações na Bovespa. O caráter especulativo da estratégia de negócios desenvolvida pela GP Investimentos dentro da Gafisa é um indicador da tendência de certa preponderância da esfera financeira sobre a produtiva.

\begin{tabular}{|l|r|r|r|}
\hline \multicolumn{1}{|c|}{ Nome } & \multicolumn{1}{c|}{ \%ON } & \multicolumn{1}{c|}{ \%PN } & \multicolumn{1}{c|}{ \%Total } \\
\hline Merrill Lynch International & 3,56 & 0 & 3,56 \\
\hline Landia Negócios Imobiliários Ltda & 0,24 & 0 & 0,24 \\
\hline Eduardo Rossi Cuppoloni & 3,55 & 0 & 3,55 \\
\hline Renata Rossi Cuppoloni & 0,1 & 0 & 0,1 \\
\hline OrbisInvestment Management Limited & 13,26 & 0 & 13,26 \\
\hline Eduardo Alfredo Levy Júnior & 0 & 0 & 0 \\
\hline Leonardo Nogueira Diniz & 0,35 & 0 & 0,35 \\
\hline Renato Gamba Rocha Diniz & 0,25 & 0 & 0,25 \\
\hline Jopar Administração Ltda. & 11,15 & 0 & 11,15 \\
\hline Joao Rossi Cuppoloni & 7,04 & 0 & 7,04 \\
\hline Rodrigo Moraes Martins & 0,17 & 0 & 0,17 \\
\hline Hilda Maria Rossi Cuppoloni & 0,22 & 0 & 0,22 \\
\hline Arpoador Adm. E Part. Ltda & 0,15 & 0 & 0,15 \\
\hline Rafael Rossi Cuppoloni & 0,96 & 0 & 0,96 \\
\hline GicBrazil Private Limited (ex Reco Aster) & 6,54 & 0 & 6,54 \\
\hline Vinci Equities Gestora de Recursos Ltda & 10,06 & 0 & 10,06 \\
\hline Outros & 39,98 & 0 & 39,98 \\
\hline Ações Tesouraria & 2,42 & 0 & 2,42 \\
\hline Total & 100 & 0 & 100 \\
\hline
\end{tabular}

Quadro 4 - Composição acionária da Rossi Residencial: out./2015. Fonte: BM\&FBovespa, 2015

Nota-se o procedimento típico dos fundos globais denominados Private Equity, que adquirem participações de capital em empresas com potencial de expansão e valorização e preparam a abertura de seu capital em Bolsas de
Valores, para novamente lucrar com a valorização das ações, além da remuneração obtida com os lucros decorrentes da própria expansão dos negócios da empresa, nesse caso da Gafisa. A compra da Tenda, uma 


\section{FINANCEIRIZAÇÃO DAS EMPRESAS DA CONSTRUÇÃO CIVIL E VERTICALIZAÇÃO EM LONDRINA-PR, BRASIL}

incorporadora atuante no segmento residencial econômico, foi parte da estratégia da Gafisa.

Em Londrina até o momento, a Tenda realizou um único empreendimento residencial: o FIT Residencial Terra Bonita, situado em área valorizada na porção sudoeste da malha urbana de Londrina, mais distante da Gleba Palhano, cuja exploração pelas incorporadoras deve prosseguir nos próximos anos. A descrição da inserção das empresas financeirizadas (Thá, Rossi Residencial, Tenda e MRV) no mercado imobiliário londrinense permite apontar para um acirramento da concorrência com as empresas de capital fechado local. Essa concorrência, até o momento, tende a se concentrar no segmento de habitação popular de mercado. Há um amplo domínio das construtoras locais sobre os segmentos de alto e médio padrão, incluindo os lançamentos voltados para consumidores e investidores interessados em apartamentos de luxo. Contudo, dado o poder financeiro dos novos concorrentes, é possível, embora ainda não seja provável, que mesmo esse domínio estabelecido possa ser disputado.

Os elementos colocados evidenciam que o mercado imobiliário londrinense se tornou alvo de disputas entre empresas oligopólicas, com poder suficiente para direcionar os rumos da produção da cidade. Para explicitar outras dimensões envolvidas na conformação desse mercado e dar contornos às alterações na concorrência com a chegada de agentes externos financeirizados, delineia-se aspectos das transformações que se sucederam em termos da formação socioespacial da qual Londrina faz parte. Para essa sucinta discussão, aponta-se mudanças na inserção da cidade e da região na divisão territorial do trabalho, como forma de dar materialidade ao conceito de situação geográfica.

\section{FINANCEIRIZAÇÃO NA CONSTRUÇÃO CIVIL E AGENTES EXTERNOS EM LONDRINA}

A atual situação geográfica de Londrina na qual as incorporadoras financeirizadas se inserem é parte de um longo processo de transformações na dinâmica da divisão territorial do trabalho. A produção de edifícios verticais em Londrina atende a condições gestadas em período mais recente, a partir dos anos 1970. Até então a dinâmica formação socioespacial na escala regional do Norte do Paraná e sua participação na Divisão Internacional do Trabalho baseavam-se em atividades agrícolas, através da produção e exportação de café, gêneros alimentícios para mercado interno e matérias primas para a indústria (BRAGUETO, 2007; FRESCA, 2004).

A substituição da produção cafeeira por lavouras temporárias, assentadas sobre uma nova base produtiva técnica e social, com o cultivo de grãos (soja, trigo e milho), alterou em grande parte a dinâmica econômica da cidade e a produção do espaço na escala regional. Em Londrina se desenvolve a oferta de produtos e serviços para atender demandas da agricultura tecnicizada (insumos, máquinas, equipamentos, serviços diversos), oriundas do aprofundamento da divisão do trabalho entre campo e cidade. A partir da expansão dos agronegócios (GONÇALVES, 2005), tem-se a presença de Bolsa de Cereais e Mercadorias em Londrina, demonstrando profundos vínculos da agricultura com o capital financeiro. Ao mesmo tempo, a industrialização dos produtos agrícolas foi ampliada. Dessa forma, parcela importante do Norte do Paraná inseriu-se nessas atividades por meio da produção e exportação de soja, seja in natura ou processada em suas diferentes etapas, tanto por cooperativas como por empresas privadas nacionais. Mas não foram apenas transformações na agricultura, porque, a partir dos anos de 1990, intensificou-se a criação de aves e seu processamento, tanto por empresas locais como por filiais de corporações nacionais e internacionais, cuja produção continua sendo destinada à exportação.

Nesse sentido, o controle de atividades produtivas passou a ser realizado pelas maiores cidades, conjunto no qual se inclui Londrina. A partir de então, a cidade continuou a controlar vasta parcela da produção da soja, trigo e milho, através de escritórios de comercialização (de 


\section{FINANCEIRIZAÇÃO DAS EMPRESAS DA CONSTRUÇÃO CIVIL E VERTICALIZAÇÃO EM LONDRINA-PR, BRASIL}

cooperativas, empresas nacionais); transporte da produção, sistema bancário como a Regional do Banco do Brasil; de muitos serviços direcionados à agropecuária, além de ser a sede da Embrapa-Soja e do Instituto Agronômico do Paraná. Essas considerações são importantes, porque os agronegócios têm parcela importante de contribuição na geração de rendas para vasta parcela de produtores rurais, cujos estabelecimentos predominantes são aqueles com área de até 100 ha (IBGE, 1996), muitos dos quais reinvestem seus ganhos na aquisição de imóveis; para trabalhadores do comércio e serviços vinculados a essa produção. Outra consideração importante em direção às alterações na divisão do trabalho diz respeito ao fato de que Londrina consolidou sua posição como cidade mais importante de uma aglomeração urbana (constituída a partir dos anos 1970), que envolve mais de um milhão de habitantes, cujas cidades menores têm fortes relações de interdependência com a principal. Nesse sentido, o papel de controle da produção agropecuária não é apenas municipal, mas envolve outros municípios, aqueles da aglomeração urbana e outros do norte do estado.

Se, por um lado, os agronegócios têm tal participação, a indústria de transformação é a terceira maior geradora de empregos (atrás dos serviços e do comércio). A produção industrial londrinense é diversificada, com predomínio de micro e pequenas empresas, concentradas nos ramos calçados, vestuário e artefatos de tecidos, bebidas e alimentos, químico, metalúrgica e mecânica (SAAB, 2014). Mas também conta com grandes empresas de capital nacional: Confepar, cooperativa do ramo lácteo, ocupando a 9.a posição dentre as maiores do Brasil (MILKPOINT, 2015); Cooperativa Integrada, que atua como agroindústria e também comercializa grãos e insumos, colocando-se como 271. a dentre as maiores cooperativas do país em 2014 (VALOR ECONÔMICO, 2015); a Cacique Café Solúvel, colocada em 591. a no ranking das 1000 maiores empresas brasileiras; Bratac (fiação de seda);
Serilon (materiais audiovisuais). Há também duas fabricantes de baterias automotivas: o Grupo Nacional de Baterias e a Rondopar, que também estão entre as maiores do setor no Brasil (CASTRO, BARROS, VEIGA, 2014). Inclui ainda unidades de negócios de corporações internacionais como a Atlas Schindler (elevadores, escadas e esteiras rolantes) e diversas fornecedoras transferidas para Londrina a partir de meados dos anos 1990 e cidades da aglomeração urbana; a BemisLatinAmerica (embalagens rígidas, flexíveis e descartáveis); a sede nacional da Adama, corporação sob controle de capital chinês que produz agroquímicos e é responsável por 15\% negócios globais da corporação, ocupando 380. a posição no ranking das 1000 maiores empresas do Brasil (VALOR ECONÔMICO, 2015).

Nos últimos 10 anos, a indústria tem participado com uma média de $20 \%$ do PIB municipal, enquanto a agropecuária representou em média 1,7\% do PIB e o terciário 76,25\% (IBGE, 2015). Em 2013, Londrina colocou-se como 43. PIB no país, representando $0,30 \%$ do nacional e a maior parcela estava no setor serviços (IBGE, 2015).

Esses apontamentos indicam uma participação na divisão internacional do trabalho concentrada, sobretudo, na exportação de grãos, carne de frango e café solúvel, enquanto a produção industrial tem um pequeno destaque. Quadro este que tem similaridade com o quadro geral do estado do Paraná, onde os principais produtos exportados são grãos, carnes, café solúvel, açúcar, madeira e adubos (FIEP, 2014). Ao mesmo tempo, é uma cidade que atrai investimentos internacionais nos segmentos comerciais varejistas: Decathlon, Wal Mart, Carrefour; no prestador de serviços: Contax (call center), Atos (francesa do segmento de tecnologia de informação), escritório da KPMG (consultoria e auditorias com sede na Suíça); negócios imobiliários (BRMalls, Sonae Sierra Brasil).

$\mathrm{O}$ que se quer ressaltar a partir desses elementos são suas implicações diretas e 


\section{FINANCEIRIZAÇÃO DAS EMPRESAS DA CONSTRUÇÃO CIVIL E VERTICALIZAÇÃO EM LONDRINA-PR, BRASIL}

indiretas com a produção da verticalização na cidade. Necessário ainda referir-se à dinâmica populacional que também passou por alterações, a começar pelo aumento no recebimento de correntes migratórias do campo para a cidade entre os anos de 1960/1980. A partir dos anos 1990 o êxodo rural perdeu vigor, sendo substituído em parte, pelas migrações oriundas de pequenas cidades da região para Londrina. Mais recentemente, o que se verifica, além da continuidade dessas últimas migrações, é a chegada de profissionais oriundos de metrópoles, requisitados por grandes empresas que demandam serviços especializados. Nesse contexto, o crescimento populacional e a diversificação dos estratos de renda passaram a intensificar a disputa pelo solo urbano, expressa na demanda por habitação. Dessa forma, o conteúdo social e profissional da cidade foi alterado, principalmente pela multiplicação de segmentos de trabalhadores ligados a atividades de serviços especializados (pesquisa, saúde, educação superior, jurídicos etc.). Constitui-se, assim, demanda diversificada para habitação, tanto no segmento popular como para segmentos de renda média e alta. Conforme IBGE (2010), do total de domicílios (164.898) permanentes por classes de rendimento mensal domiciliar, 14,9\% correspondiam àqueles acima de 10 salários mínimos; $2,4 \%$ entre mais de cinco e 10 salários mínimos; 39,6\% com rendimentos entre dois e cinco salários mínimos. Na data referida, a população total do município era 506.701 habitantes, dos quais 493.520 eram urbanos.

Algumas correlações sobre a expansão da verticalização e o início da atuação de incorporadoras financeirizadas podem ser apontadas. O primeiro aspecto é que, nos anos de 1970, foram criadas algumas construtoras em Londrina que foram gradativamente galgando degraus em termos de capacitação técnica, financeira e produção de empreendimentos. A ação dessas empresas e as condições locais favoráveis à demanda por apartamentos colocaram a cidade em destaque no cenário regional e nacional, por ser uma das mais verticalizadas do Brasil. Essas empresas locais, articuladamente com várias etapas do desenvolvimento nacional, foram se adaptando às novas condições e acabaram por se tornarem importantes na escala nacional, macrorregional e local. Para tanto, colocaram em prática diversas estratégias para expandir seus mercados consumidores (PASSOS, 2007). Esse é o caso da Plaenge, A. Yoshii, Vectra, Quadra, Galmo, Artenge, Favoreto, dentre outras, constantes no quadro 1 . Sucessivamente foram impondo mais acentuadamente - porque, desde os anos de 1950, tem-se a produção de edifícios verticais na cidade - domicílios na forma de apartamentos para mercados consumidores de diversos segmentos econômicos.

Em etapa recente, a dimensão assumida pelo processo de verticalização, a política habitacional do Governo Federal, bem como a presença de mercado consumidor extremamente diversificado, tornou a cidade atrativa para novos investimentos por parte de incorporadoras e construtoras de atuação nacional, sejam as de capital aberto ou fechado. Essas empresas buscam cidades que apresentem terras disponíveis, infraestrutura, legislação favorável (em especial com relação ao número de pavimentos permitidos); mas, acima de tudo, buscam cidades que apresentem mercado consumidor para seus produtos.

Nesse sentido, a partir do objetivo do presente artigo, que é entender as implicações do processo de financeirização de empresas da construção civil na verticalização de Londrina, verifica-se que: a) algumas construtoras e incorporadoras de capital aberto adentraram recentemente no mercado londrinense por diversos caminhos: parcerias com pequenas construtoras londrinenses; parceria com outra grande construtora nacional e independentemente; b) até o momento, as atuações dos agentes externos (construtoras de capital aberto) têm sido relativamente pequenas, quando comparadas à atuação das empresas de capital local. A exceção tem sido a $M R V$, que adotou estratégia de atuar para o denominado segmento econômico e tornou-se 


\section{FINANCEIRIZAÇÃO DAS EMPRESAS DA CONSTRUÇÃO CIVIL E VERTICALIZAÇÃO EM LONDRINA-PR, BRASIL}

uma das incorporadoras que mais produziu edifícios em Londrina, no período considerado neste trabalho; c) essas empresas enfrentam disputas muito acirradas, determinadas pela presença de empresas locais ainda capazes de ganharem a concorrência frente às novas empresas externas. Tal capacidade de enfrentamento deve-se a práticas muito consolidadas, em termos de conhecimento do mercado consumidor e suas preferências, de conhecimento dos percursos da legislação municipal, de possuírem bancos de terras bastante amplos e localizados em áreas preferenciais conforme Plano Diretor, dentre outras; d) a localização dos empreendimentos realizados pelos agentes externos na cidade, à exceção da MRV, foi bastante seletiva e direcionada para áreas valorizadas no mercado imobiliário no momento atual, tanto para empreendimentos residenciais quanto comerciais; e) exceção ainda nesse percurso é o fato de a empresa Thá ter dado continuidade nos lançamentos de empreendimentos residenciais, baseando-se na estratégia de conquistar o mercado aos poucos (NASCIMENTO, 2015); f) o fato de algumas delas só terem realizado um ou dois empreendimentos e não ofertarem mais nenhum pode estar vinculado a três aspectos: o primeiro é o fato de que a maturação de seus projetos pode levar mais tempo, e, com isso, não atender às exigências em termos de rentabilidade imposta por seus acionistas; o segundo pelo fato de que a lucratividade de seus empreendimentos pode ter sido relativamente baixa; ou ainda, pela etapa recessiva para a construção civil a partir de 2014, recrudescendo o lançamento de novos empreendimentos.

Diante desses elementos, a discussão da financeirização na construção civil deve ser realizada de modo particular, porque ela se realiza por caminhos diferentes e afeta as cidades de modo diferenciado. Isso porque a situação geográfica, conforme exposto anteriormente, "[...] constitui o resultado de ações de diversos elementos, que se dão em diferentes níveis. Esses elementos são variáveis pois mudam de significação através do tempo" (SANTOS, 1991, p. 95). Em Londrina, a financeirização da construção civil pouco alterou a dinâmica da verticalização no período estudado, pois continua sendo dominada por empresas que optaram por continuar com seus capitais fechados, denotando que as tendências gerais se realizam de modo singular nesse lugar. Esse é o permanente devir.

\section{CONSIDERAÇÕES FINAIS}

Discutir a financeirização na construção civil enquanto tendência geral para o setor no Brasil perpassa, obrigatoriamente, por estabelecer um processo de "filtragem" com base na situação geográfica estudada. Em outros termos, quando uma tendência geral está colocada, a sua realização nos lugares exige entender que esses acolhem ou repelem-na total ou parcialmente. Mesmo a acolhendo, realiza-a de forma particular mediante sua história, interesses e força dos diferentes agentes sociais existentes na situação analisada.

Assim, a financeirização das construtoras e incorporadoras e seus efeitos na verticalização em Londrina são muito pouco importantes até o presente momento. Isso porque o lugar acolheu a tendência, mas o modo como vem se dando esse evento foi mediado e redefinido pelas estruturas presentes. As formas pelas quais se desenvolve a construção civil na cidade frearam, até certo ponto, o avanço dos agentes externos representados, nesse caso, pelas empresas financeirizadas. A análise geográfica aplicada à dinâmica da verticalização em Londrina revelou que, nem sempre, variáveis externas, por mais força que tenham em outros contextos, conseguem se sobrepor de imediato às variáveis internas. Por outro lado, a presença dos novos agentes externos financeirizados revela a complexidade da produção do espaço na aglomeração urbana, na qual Londrina é a cidade principal. Apesar das particularidades ressaltadas, o processo de financeirização de empresas da construção civil presente em Londrina demonstra que a cidade e sua aglomeração apresentam também dinâmicas 


\section{FINANCEIRIZAÇÃO DAS EMPRESAS DA CONSTRUÇÃO CIVIL E VERTICALIZAÇÃO EM LONDRINA-PR, BRASIL}

que, em geral, são mais explicitas e intensas nas maiores metrópoles brasileiras.

\section{AGRADECIMENTOS}

Ao CNPq pelo apoio financeiro à realização da pesquisa.

\section{REFERÊNCIAS}

BALL, Michel. O desenvolvimento do capitalismo na provisão da habitação. Espaço e Debates, São Paulo, v. 12, n. 36, p. 11-34, 1992,

BIANCARELI, A. M.; LODI, A. L. Financiamento ao setor imobiliário. In: Projeto de estudos sobre perspectivas da indústria financeira brasileira e o papel dos bancos públicos: Subprojeto mercado de crédito bancário. Campinas: BNDES, FECAMP, CECON-IEUNICAMP/IE-UFRJ, 2009.

BM\&FBOVESPA. Rossi Residencial S. A.: posição acionária em setembro de 2015. Disponível em: $<$ http://www.bmfbovespa.com.br/CiasListadas/Empresas-

Listadas/ResumoEmpresaPrincipal.aspx?codigo Cvm=16306\&idioma=pt-BR $>$. Acesso em novembro de 2015.

BOLAFFI, G. BNH: bode expiatório. Novos Estudos Cebrap, São Paulo, n. 13, p. 45-55, 1985.

BONDUKI, Nabil G. Do projeto Moradia ao programa Minha Casa, Minha Vida. Teoria e Debate, São Paulo, n. 82, p. 8-14, 2009.

BONDUKI, Nabil G. Origens da habitação social no Brasil. Análise Social, São Paulo, v. 29, n. 3, p. 711-732, 1994.

BOTELHO, A. A cidade como negocio: uma produção do espaço e acumulação do capital no município de São Paulo. Cadernos Metrópole, São Paulo, v.18,p. 15 - 38, 2007.

BRAGUETO, C. R. O aglomerado urbanoindustrial de Londrina: sua constituição e dinâmica industrial. 2007. Tese (Doutorado em Geografia) - USP, São Paulo.
BRASIL. Lei 10.406, de 10 de janeiro de 2002. Institui o Código Civil. Disponível em: $<$ http://www.planalto.gov.br/ccivil 03/leis/200 2/L10406compilada.htm > . Acesso em outubro 2015.

BRASIL. Lei 10931 de 02 de agosto de 2004. Dispõe sobre o patrimônio de afetação de incorporações imobiliárias, Letra de Crédito Imobiliário, Cédula de Crédito Imobiliário, Cédula de Crédito Bancário, altera o DecretoLei n. 911, de 1 de outubro de 1969, as Leis no4.591, de 16 de dezembro de 1964, no 4.728, de 14 de julho de 1965, e no 10.406, de 10 de janeiro de 2002, e dá outras providências. Disponível em:

$<$ http://www.planalto.gov.br/ccivil 03 $\angle$ ato2004-2006/2004/lei/l10.931.htm>. Acesso em 06/06/2015.

BRASIL. Lei 9514 de 20 de novembro de 1997.Dispõe sobre o Sistema de Financiamento Imobiliário, institui a alienação fiduciária de coisa imóvel e dá outras providências.

Disponível em <http://www.planalto.gov.br/ccivil 03/LEIS/L9 514.htm > Acesso em 06/06/2015.

CASARIL, C. C. Meio século de verticalização urbana em Londrina-PR e sua distribuição espacial: 1950-2000. 2008. Dissertação (Mestrado em Geografia) - Universidade Estadual de Londrina, Londrina.

CASARIL, C. C. Formação sócio-espacial de Londrina-PR e seu processo precoce de verticalização urbana. Revista Discente Expressões Geográficas, Florianópolis, v. 7, p. 32-53, 2011.

CASARIL, C. C. Algumas notas sobre o processo e a espacialização da verticalização urbana na cidade de Londrina: 1950-2000. Caminhos de Geografia, Uberlândia, v. 11, p. 1 - 22, 2010.

CASTRO, B. H. R.; BARROS, D. C.; VEIGA, S. G. Baterias automotivas: panorama da indústria no Brasil, as novas tecnologias e como os veículos elétricos podem transformar o mercado global. BNDES Setorial, Rio de Janeiro, n. 37, p. 443496, 2013. 


\section{FINANCEIRIZAÇÃO DAS EMPRESAS DA CONSTRUÇÃO CIVIL E VERTICALIZAÇÃO EM LONDRINA-PR, BRASIL}

CASTRO, C. M. P.; SHIMBO, L. Z.. Das cooperativas autofinanciadas às construtoras $\mathrm{e}$ incorporadoras de capital aberto: a ampliação do mercado habitacional. Revista Brasileira de Estudos Urbanos e Regionais (ANPUR), São Paulo, v. 12, p. 53-74, 2010.

CHESNAIS, F. (Org). A finança mundializada. São Paulo: Boitempo, 2005.

CORRÊA, R. L. O espaço urbano. São Paulo: Ática, 1995.

DIEESE. A evolução do crédito na economia brasileira: 2008-2013. Nota Técnica, São Paulo, n. 135, p. 1-31, 2014. Disponível em: <http://www.dieese.org.br/notatecnica/2014/ notaTec135Credito.pdf $>$. Acesso em: novembro de 2015.

ECONOINFO. Posição acionária. Disponível em: <http://www.econoinfo.com.br/governancacorporativa/posicaoacionaria?codigoCVM=20915> Acesso em 29/09/2015.

EMPORIS. Buildingdirectory: Londrina. Disponível em:

http://www.emporis.com/city/103081/londrin a-brazil>. Acesso em dezembro de 2015.

FIEP. Balança comercial: exportações e importações: janeiro 2014. Disponível em: <http://www.fiepr.org.br/cinpr/servicoscin/int eligencia-

comercial/uploadAddress/Balanca $012014[60$ 958].pdf> . Acesso em novembro de 2015.

FIX, M. A. B. Financeirização e transformações recentes no circuito imobiliário no Brasil. 2011. Tese (Doutorado em Economia) Instituto de Economia, Unicamp, Campinas.

FIX, M. Uma ponte para a especulação: a arte da renda na montagem de uma cidade global. Caderno CRH (UFBA), Salvador, v. 22, p. 41-64, 2009.

FRESCA, T. M. Industrialização no norte do Paraná na década de 1990: transferência industrial e estratégias de crescimento. Ciência Geográfica, Bauru, v. 10, n. 3, p. 195-206, 2004.
GONÇALVES, José S. Agricultura sob a égide do capital financeiro: passo rumo ao aprofundamento do desenvolvimento dos agronegócios. Informações Econômicas, São Paulo, v. 35, n. 5, p. 7-36, 2005.

HILFERDING, R.O capital financeiro. São Paulo: Nova Cultural, 1985.

IBGE. Produto Interno Bruto dos Municípios 2010-2013. Disponível em:

<http://biblioteca.ibge.gov.br/visualizacao/livro s/liv95014.pdf > Acesso em 23 de dezembro de 2015.

IBGE. Censo demográfico: 2010. Rio de Janeiro, IBGE, 2010.

LÊNIN, V. I. Imperialismo:fase superior do capitalismo. São Paulo: Global Editora, 1979.

LONDRINA, PREFEITURA MUNICIPAL. Lei $\mathrm{n}$. 10.850, DE 29 DE DEZEMBRO DE 2009. Altera dispositivos da Lei Municipal n.o 10.730, de 01 de julho de 2009, para o fim de ampliar a abrangência do Programa Minha Casa Minha Vida e dá Outras Providências.

LONDRINA, PREFEITURA MUNICIPAL. Lei no 11.381 de 21 de novembro de 2011. Institui o Código de Obras e Edificações do município de Londrina. Disponível em:

http://www1.londrina.pr.gov.br/dados/images/ stories/Storage/sec obras/legislacao/LEI \%201 13812011 Codigo de Obras.pdf >. Acesso em novembro de 2015.

MELO, M. A. B. C. de. Regimes de acumulação, Estado e articulação de interesses na produção do espaço construído (Brasil, 1940-1988). In: VALLADARES, L.; PRETECEILLE, E. (orgs.).

Reestruturação urbana: tendências e desafios. Rio de Janeiro: Nobel/IUPERJ, 1990.

MILKPOINT. Ranking leite Brasil: captação das maiores empresas cresce 5,9\% em 2014. Disponível em: <http://www.milkpoint.com.br/cadeia-doleite/giro-lacteo/ranking-leite-brasil-captacaodas-maiores-empresas-cresce-59-em-201494625n.aspx>. Acesso em: out. 2015. 


\section{FINANCEIRIZAÇÃO DAS EMPRESAS DA CONSTRUÇÃO CIVIL E VERTICALIZAÇÃO EM LONDRINA-PR, BRASIL}

MRV. Institucional: cidades atendidas.

Disponível em:

http://www.mrv.com.br/institucional/cidadesa

tendidas >. Acesso em: setembro de 2015.

NASCIMENTO, C. F. A verticalização de

Londrina-PR: financeirização e mercado imobiliário entre 2000-2013. 2015. Dissertação (Mestrado em

Geografia) - UEL, Londrina.

PASSOS, V. R. de L. A verticalização de Londrina: 1970/2000: a ação dos promotores imobiliários. 2007. Dissertação (Mestrado em Geografia) - UEL, Londrina-PR.

PINTO, N. P. A. O capital financeiro na economia contemporânea: uma revisão teórica e histórica de seu papel no desenvolvimento recente dos Estados Unidos. 1994. Tese (Doutorado) - UNICAMP, Campinas.

ROSSI. A empresa: sobre a Rossi. Disponível em:

<http://www.rossiresidencial.com.br/institucio nal/sobre-a-rossi>. Acesso em 29/09/2015.

ROYER, L. Financeirização da política

habitacional: limites e perspectivas. 2009. Tese (Doutorado) - FAU/USP, São Paulo.

$\mathrm{SAAB}, \mathrm{T}$. B. As micro e pequenas empresas e a dinâmica industrial londrinense: 1992-2011. 2014. Dissertação (Mestrado em Geografia) UEL, Londrina.

SANFELICI, D. Financeirização e a produção do espaço urbano no Brasil: uma contribuição ao debate. EURE, Santiago, v. 39, n. 118, p. 27-46, 2013.

SANTOS, M. Metamorfoses do espaço habitado. São Paulo: Hucitec, 1991.

SANTOS, M. Espaço e sociedade: ensaios. 2a ed. Petrópolis: Vozes, 1982.

SÃO PAULO, PREFEITURA MUNICIPAL. Lei $\mathrm{n}$. 11.228/92. Dispõe sobre as regras gerais e específicas a serem obedecidas no projeto, licenciamento, execução, manutenção e utilização de obras e edificações, dentro dos limites dos imóveis; revoga a Lei no 8.266, de 20 de junho de 1975, com as alterações adotadas por leis posteriores, e dá outras providências. Disponível em:

http://www.prefeitura.sp.gov.br/cidade/secret arias/subprefeituras/upload/pinheiros/arquivos $\angle C O E$ 1253646799.pdf >. Acesso em setembro de 2015 .

SHIMBO, L. Z. Habitação social de mercado: a confluência entre Estado, empresas construtoras e capital financeiro. Belo Horizonte: C/Arte, 2012.

TONE, B. B. Notas sobre a valorização imobiliária em São Paulo na era do capital fictício. 2010. Tese (Doutorado em Arquitetura) - USP, São Paulo.

VALOR ECONÔMICO. Valor 1000: 2015. Disponível em:

<http://www.valor.com.br/valor1000/2015/ran king1000maiores $>$. Acesso em setembro de 2015.

VARGAS, Nilton. Tendências de mudança na indústria da construção. São Paulo. Espaço e Debates, São Paulo, a. 12, n. 36, p. 47- 53, 1992

VEDROSSI, A. O. A securitização de recebíveis imobiliários: uma alternativa de aporte de capitais para empreendimentos residenciais no Brasil. 2002. Dissertação (Mestrado em Engenharia) - Escola Politécnica, USP, São Paulo.

VERDI, Adriana Renata. Grupos econômicos e territórios locais: Alcatel e Renault no Brasil. 2002. Tese (Doutorado em Geografia) - USP, São Paulo. 